\title{
Farmland function evolution in the Huang-Huai-Hai Plain: Processes, patterns and mechanisms
}

\author{
ZHANG Yingnan ${ }^{1,2,3}$, ${ }^{*}$ LONG Hualou ${ }^{1,3,4}$, MA Li $^{1,2,3}$, GE Dazhuan ${ }^{1,2,3}$, \\ TU Shuangshuang ${ }^{1,3,5}, \mathrm{QU} \mathrm{Yi}^{1,2,3}$
}

1. Institute of Geographic Sciences and Natural Resources Research, CAS, Beijing 100101, China;

2. University of Chinese Academy of Sciences, Beijing 100049, China;

3. Center for Assessment and Research on Targeted Poverty Alleviation, CAS, Beijing 100101, China;

4. College of Resources and Environment, University of Chinese Academy of Sciences, Beijing 100049, China;

5. Key Laboratory of Environment Change and Resources Use in Beibu Gulf, the Ministry of Education, Guangxi Teachers Education University, Nanning 530001, China

\begin{abstract}
Using counties as the basic analysis unit, this study established an evaluation index system for farmland function (FF) from economic, social, and ecological perspectives. The method combining entropy weighting and multiple correlation coefficient weighting was adopted to determine the weights, and the FF indices were calculated for each county. Subsequently, the spatio-temporal characteristics of farmland function evolution (FFE) were analyzed and the coupled relationships between the sub-functions were explored based on a coupling coordination model. At the same time, the dynamic mechanism of FFE was quantitatively analyzed using a spatial econometric regression analysis method. The following major conclusions were drawn: (1) The farmland economic function generally exhibited a declining trend during 1990-2010, and it is essential to point out that it was stronger in underdeveloped and agriculture-dominated counties, while it continuously weakened in developed areas. Farmland social function decreased in $60.29 \%$ of the counties, whereas some counties, which were mostly located in north of Zhengzhou and west of Dezhou and Cangzhou, Yantai, and Weihai, clearly increased. A dramatic decline in farmland ecological function occurred around Beijing, Tianjin, and Jinan. Areas located in the northern part of Henan Province and the central part of Shandong Province saw an increase in ecological function. (2) There was a significant spatial difference in the coupling degree and coordination degree of the sub-functions, and the decoupling phenomenon highlighted this. The changes in social function and ecological function lagged behind economic function in developed areas, but these were highly coupled in some underdeveloped areas. (3) FFE in the Huang-Huai-Hai Plain (HHHP) is resulted from the comprehensive effects of regional basic conditions and external driving factors. Furthermore, the transitions of population and industry under urbanization and industrialization played a decisive role in the evolution intensity and direction of farmland sub-systems, including the economy, society, and the ecology. According to the results mentioned above, promoting the transformation from traditional agriculture to modern agriculture
\end{abstract}

Received: 2017-11-25 Accepted: 2017-12-28

Foundation: Key Program of National Natural Science Foundation of China, No.41731286

Author: Zhang Yingnan (1993-), PhD, specialized in urban-rural development and land use. E-mail: zhangyn.16b@igsnrr.ac.cn

"Corresponding author: Long Hualou (1971-), PhD and Professor, specialized in rural restructuring, urban-rural development and land use transition. E-mail: longhl@igsnrr.ac.cn 
should be regarded as an important engine driving sustainable development in the HHHP. Taking different regional characteristics of FFE into account, differentiated and diversified farmland use and management plans should be implemented from more developed urban areas to underdeveloped traditional agricultural areas.

Keywords: land use transition; urbanization; spatio-temporal pattern; function index; coupling and coordination degree; coupling effect

\section{Introduction}

Since the 1990s, China's rural-urban spatial and industrial structures have rapidly transformed (Long et al., 2016). The convergence of population and industry has fueled the expansion of urban space (Li et al., 2017). The transfer of rural-urban elements has resulted in serious problems, including farmland nonagriculturalization, non-grain preference, extensive cultivation, and farmland marginalization (Song, 2017). The disorderly competition between the great demand and limitied farmland resources, as well as the management mode that neglecting the derivative functions, have caused a series of eco-environmental problems, such as land degeneration, soil acidification (Song et al., 2014). Traditonal farmland management mode oriented around a single function is incompatible with the multiple demands of urban-rural residents (Ülo et al., 2007). Exploring new land management policies from the perspective of multifunctional land management has aroused wide attention among numerous scholars (Jongeneel et al., 2008). In recent years, a large number of researches have been conducted on farmland function (FF) (Song and Ouyang, 2012a; Vereijken, 2003; Jiang et al., 2011), such as impact assessments (Sal and García, 2007; Potschin and Haines-Young, 2008; Todorova and Ikova, 2014), farmland value estimation (Rong et al., 2014), spatio-temporal evolution (Song et al., 2015; Yang and Tan, 2014), and multifunctional farmland management (Song and Ouyang, 2012b). With regard to single functions, existing studies have mainly been concerned with the functions of social security (Wu et al., 2013) and ecosystem services (Song et al., 2013). Few scholars subdivide economic and social functions into more detailed components for in-depth study (Chen et al., 2016; Ke et al., 2016). Furthermore, only a minority of scholars have explored the coupled relationships between socio-economic development and function change (Tian, 2014), and quantitative analysis is rarely applied in these studies.

Farmland use system, which combines economic, social, and ecological sub-systems, generally functions as promoting economic growth, sustaining social prosperity, and conserving eco-environment (Zhou et al., 2016). And the three sub-systems of that show symbiosis and synergy relationships in normal circumstances. Although multifunctional farmland transitions have generally occurred in China, the decoupling between the sub-functions that has resulted from unmatched supply and demand, and morphological distortion, is becoming increasingly prominent (Song et al., 2015). Undoubtedly, the Huang-Huai-Hai Plain (HHHP), one of the main grain-producing areas, plays an important role in national food security. In 2014, farmland area in this region amounted to 27.42 million $\mathrm{hm}^{2}$, which accounted for $65.8 \%$ of the total land area and $81.81 \%$ of the ecological land in the HHHP. The per capita farmland area was about $1100 \mathrm{~m}^{2}$, which was $8.5 \%$ higher than the national average. During 1990-2014, farmland area decreased by 150 thousand $\mathrm{hm}^{2}$ annually and the farmland nonagriculturalization rate reached $18 \%$. In 2014, the area planted 
with grain was 23.19 million $\mathrm{hm}^{2}$ and was $1.38 \%$ higher than that in 1990 , but the proportion of grain in the total crop area reduced from $80.98 \%$ to $73.49 \%$. The increasing grain demand imposes enormous pressure on farmland and water resources, thus causing serious environmental deterioration and groundwater level decline (Liu et al., 2015). The water resources per unit farmland area are about $1 / 8$ of the national average and the largest groundwater depression funnel appeared in the HHHP (Zhang and Kong, 2014). With rapid urbanization and industrialization, and sharp urban expansion, critical food security issues and the diverse demands of urban-rural residents pose great challenges to sustainable and multifunctional land use (Liu et al., 2014). Therefore, this paper chose counties as the basic unit to explore the spatio-temporal characteristics and dynamic mechanisms of farmland function evolution (FFE) in the HHHP. Based on the spatio-temporal patterns of each sub-function, a coupling coordination model was adopted to analyze the coupling relationship between the three sub-functions. Finally, the dynamic mechanisms for FFE were quantitatively analyzed using spatial econometric regression. Carrying out this research at the county level provided a detailed depiction of regional differences and was of significance in farmland spatial allocation, multifunctional land management, and providing scientific support for sustainable land use.

\section{Study area and data sources}

\subsection{Study area}

The HHHP, one of the main grain-producing areas for agricultural products, stretches across seven provinces, including Beijing, Tianjin, Shandong, Hebei, Henan, Anhui, and Jiangsu (Figure 1). Suitable climatic conditions and abundant farmland resources have generated a unique dense rural population. The number of rural residents was approximately 180 million in 2014 , which accounted for $80.92 \%$ of the total in the HHHP and $29.11 \%$ of the total rural population in China. The number of rural employees was over 110 million, and the proportion of employees who engaged in primary, secondary, and tertiary industries was 1:0.45:0.40. With the development of agriculture, the added value of the primary industry made up $13.29 \%$ of GDP and the per-capita net income for farmers was about 11,000 yuan. Additionally, challenges to the growth of grain yield, including farmland nonagriculturalization and non-grain preference, have become the foremost factors that limit regional sustainable socio-economic development.

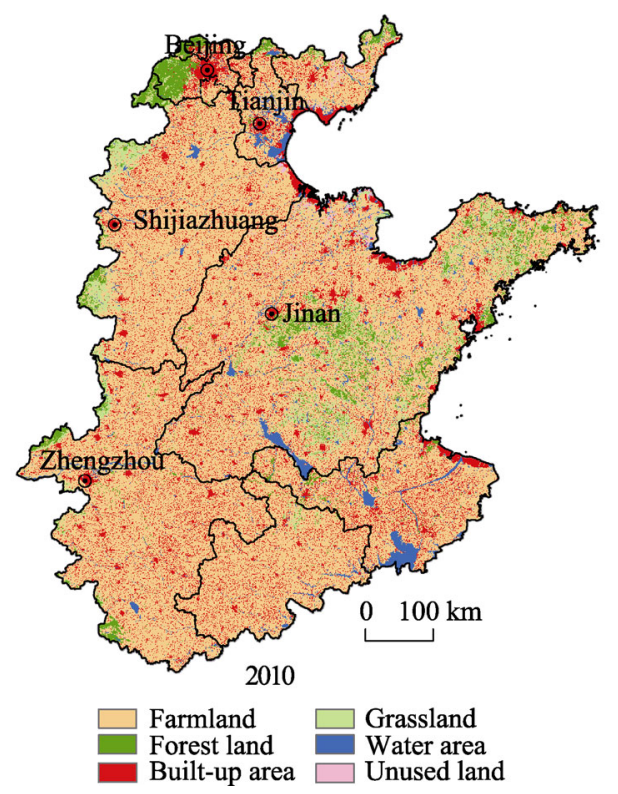

Figure 1 Regional profile of the study area

\subsection{Data sources}

Vector data for land use $(1990,2000$, and 2010) that adopted the standard land use classifi- 
cation system published in 2007 (GB/T 21010-2007) was interpreted from Landsat TM images with a spatial resolution of $30 \mathrm{~m} \times 30 \mathrm{~m}$ provided by the Ministry of Land and Resources of the People's Republic of China. Socio-economic data at the county level mainly originated from China Statistical Yearbook (County Level) (2001-2011), China Statistical Yearbook for Regional Economy (2001-2011), and Statistical Summary of the Rural Economy at the County Level (1991). Population data was obtained from 2010 Population Census Data of China, 2000 Census Data of the Cities or Counties, 1990 Census Data of the Cities or Counties, and China Statistical Yearbook (1990, 2000, and 2010). In the process of preparing the dataset, the statistic yearbook for each province was used to ensure the accuracy of the data when revising and checking. A digital elevation model (DEM) for calculating the average elevation of each county, major rivers, and average precipitation was derived from the National Geomatics Center of China (http://nfgis.nsdi.gov.cn). The potential crop yield of China, and vector data for highways and railways, were provided by Data Center for Resources and Environmental Sciences, Chinese Academy of Sciences (RESDC) (http://www.resdc.cn). Considering the adjustment of administrative divisions and the fact that a small number of counties lack socio-economic data, some municipal districts and counties were removed from this study, leaving a final total of 340 counties.

\section{Concept and methodology}

\subsection{Farmland function}

Meeting the demands of subsistence and development, which is regarded as the essence of $\mathrm{FF}$, is both the endogenous dynamic and the ultimate goal of farmland development and utilization (Song and Ouyang, 2012b). Farmland management with both commodity and non-commodity output results in a multifunctional complex of material production and non-material production. The demand for farmland tends to be diversified and high-end as the advancement of society and the economy, which reflects the transformation from emphasizing traditional economic value to focusing on the multiple values of the economy, society, and ecology. Based on grain or other cash crop production, the economic function brings financial gains to rural households and promotes national economic development. Generally, social function indirectly manifests as providing basic employment for farmers, maintaining social stability, and ensuring food security. Undoubtedly, farmland plays an important role in ensuring regional and national food security because of its status of major production base of agricultural products. Therefore, the function of ensuring food security was not taken into consideration, while the function of guaranteeing employment was emphasized in this paper. Ecological function mainly embodies as preserving biological diversity, regulating the climate, purifying the environment, maintaining the resilience of field ecosystems, and enhancing the landscape esthetic. Farmland, the functions of which are constrained by multiple factors, such as human activity, individual concept and consciousness, regional cultural traditions, socio-economic systems and policies, and farmland ecosystem carrying capacity, is the coupling of the natural ecological sub-system and the artificial sub-system. Furthermore, an FF system is a synthesis formed by interrelated and interacting sub-functions, rather than the simple superposition of every single function (Matson 
et al., 1997; Zhou et al., 2016).

\subsection{Assessing farmland functions}

\subsubsection{Establishing an evaluation index system}

Considering data accessibility and the difficulty of quantification, an evaluation index system covering economic, social, and ecological functions was established by following scientific, systematic, and hierarchical principles (Table 1). (1) In order to evaluate economic function scientifically, the yield, output value, and potential crop yield of farmland were taken into consideration. The output value of crop farming (lópez-ridaura et al., 2005; Fleskens et al., 2009) and grain yield per unit farmland area (Sal and García, 2007; Tan, 2014) comprehensively reflect the output level affected by natural conditions and varying degrees of input production factors. Based on farmland spatial distribution, soil conditions, and elevation, the GAEZ (Global Agro-Ecological Zones) model, which incorporates natural factors, pest, and disease damage, was adopted to calculate potential farmland crop yield (Evans and Fischer, 1999). (2) When selecting the indices for social function evaluation, the emphasis was placed on farmland carrying capacity of rural labor employment and the effects of agricultural mechanization on farmers' employment. As a rule, the larger the per capita farmland area is, the stronger its employment absorption capacity (Song, 2013; Hu et al., 2014). Small-scale and dispersive management with lower earnings gives rise to the transfer of rural labor from traditional agriculture to non-agricultural industries. The proportion of workers who engaged in agriculture, forestry, animal husbandry, and fisheries can directly reflect the reliance of famers on farmland (Luo and Cai, 2016; Li and Han, 2007). The total power of agricultural machinery per unit farmland area is the firsthand measurement of agricultural mechanization (Verma, 2006; Zhu, 2005). The increase of labor-saving

Table 1 The evaluation index system for FF

\begin{tabular}{|c|c|c|c|c|}
\hline Criteria & Index & Unit & Direction & Weight $^{3)}$ \\
\hline \multirow{4}{*}{$\begin{array}{l}\text { Economic function } \\
\text { index }\end{array}$} & Grain yield per unit farmland area & ton $/ \mathrm{hm}^{2}$ & + & 0.29 \\
\hline & $\begin{array}{l}\text { Output value of crop farming per unit farmland } \\
\text { area }\end{array}$ & yuan $/ \mathrm{hm}^{2}$ & + & 0.28 \\
\hline & Potential crop yield of farmland & $\mathrm{kg} / \mathrm{hm}^{2}$ & + & 0.43 \\
\hline & Per capita farmland area & $\mathrm{hm}^{2} /$ person & + & 0.53 \\
\hline \multirow[t]{2}{*}{ Social function index } & $\begin{array}{l}\text { Proportion of the employees who engaged in } \\
\text { agriculture, forestry, animal husbandry, and } \\
\text { fisheries in the total number of rural em- } \\
\text { ployees }\end{array}$ & $\%$ & + & 0.21 \\
\hline & $\begin{array}{l}\text { Total power of agriculture machinery per } \\
\text { unit farmland area }\end{array}$ & $\mathrm{kW} \cdot \mathrm{h} / \mathrm{hm}^{2}$ & - & 0.26 \\
\hline \multirow{4}{*}{$\begin{array}{l}\text { Ecological function } \\
\text { index }\end{array}$} & $\begin{array}{l}\text { The equivalent quantity of fertilizer input } \\
\text { per unit farmland area exceeds the upper } \\
\text { limit of the safety standard of fertilizer input } \\
\text { per unit farmland area }{ }^{1)}\end{array}$ & $\mathrm{kg} / \mathrm{hm}^{2}$ & - & 0.17 \\
\hline & Population per unit farmland area & Person $/ \mathrm{hm}^{2}$ & - & 0.25 \\
\hline & Percentage of farmland in ecological land ${ }^{2)}$ & $\mathrm{hm}^{2}$ & + & 0.32 \\
\hline & Function index of landscape aesthetics & - & + & 0.26 \\
\hline
\end{tabular}

Note: 1) The upper limit of the international safety standard of fertilizer input per unit farmland area is $225 \mathrm{~kg} / \mathrm{hm}^{2} ; 2$ ) Ecological lands mentioned in this paper include farmland, forest land, grassland, water bodies, and unused land (Long et al., 2015); 3) A method combining entropy weighting and multiple correlation coefficient weighting was used to determine indices' weights (Luo and Cai, 2016). 
inputs may lower the dependence of agricultural production and management on rural labor, thus weakening the employment carrying capacity of farmland. Ecological pressures due to yield-increasing inputs and population growth, which were depicted by the excess fertilizer input and the quantity of population per unit farmland area, were taken into consideration when selecting indicators for measuring ecological function. The percentage of farmland in ecological lands represents the importance of farmland to eco-environmental security, due to the large share of farmland in the HHHP (Sun et al., 2007). In the process of evaluating landscape aesthetic function, the concentration of farmland and accessibility were emphasized, and the relief amplitude was ignored due to the flat terrain and smaller spatial heterogeneity in the HHHP (Peng et al., 2016). It is generally accepted that centralized and contiguous farmland has greater aesthetic value. Farmland is more attractive for urban residents compared to rural residents. However, distance and accessibility determine where urban dwellers will go.

\subsubsection{Calculating FF index}

The first step was to standardize the evaluation indicators using the maximum difference normalization method. Then, each sub-function index was calculated by the formulas below:

$$
\begin{aligned}
& F(\text { econ })=\sum_{i=1}^{n} w(\text { econ })_{i} * f(\text { econ })_{i} \text { or } F(\text { soci })=\sum_{i=1}^{n} w(\text { soci })_{i} * f(\text { soci })_{i} \\
& \text { or } F(\text { ecol })=\sum_{i=1}^{n} w(\text { ecol })_{i} * f(\text { ecol })_{i}
\end{aligned}
$$

where $F($ econ), $F($ soci), and $F(e c o l)$ represent economic, social, and ecological function indices, respectively. Similarly, $w(\text { econ })_{i}, w(\text { soci })_{i}$ and $w(e c o l)_{i}$ are the weights of index i for each sub-function, respectively; and $f(\text { econ })_{i}, f(\text { soci })_{i}$ and $f(e c o l)_{i}$ are the respective standardized index values. $F(e c o n), F($ soci $)$, and $F(e c o l)$ range from 0 to 1 , and the larger the value, the stronger the corresponding sub-function is.

\subsection{The coupling pattern of FFE}

There are relationships of relevance, influence, and constraints among economic, social, and ecological functions, which may have positive or negative effects on each other. Although a multi-factor comprehensive evaluation method may reflect the comprehensive function of farmland, it is unable to directly describe the coupling and coordination degree among the sub-functions (Yang et al., 2015). Hence, a coupling and coordination model was used to quantitatively depict the strength of the interaction between the three sub-functions and reveal the state of synergetic evolvement (Liu et al., 2011). The formula for the coupling degree model is as follows:

$$
C=\left[(F(\text { econ }) * F(\text { soci }) * F(\text { ecol })) /\left(\frac{F(\text { econ })+F(\text { soci })+F(\text { ecol })}{3}\right)^{3}\right]^{1 / 3}
$$

where $C$ is the coupling degree, which varies between 0 and 1 . When $C=0$, this means the relationship between the three sub-functions is disordered. On the contrary, when $C=1$, the coupling degree of each sub-function reaches the maximum, which means that they are fully coupled.

In order to further explore the degree of coordinated development, a coordination model 
was used, and the formula is below:

$$
D=\left(C^{*} T\right)^{1 / 2}, \quad T=\alpha^{*} F(\text { econ })+\beta^{*} F(\text { soci })+\gamma^{*} F(\text { ecol })
$$

where $C$ is the coupling degree and $D$ is the coordination degree; $T$ is the comprehensive evaluation index of farmland functions. A method combining entropy weighting and multiple correlation coefficients weighting was used to calculate weights. The values of $\alpha, \beta$, and $\gamma$ were $0.21,0.40$, and 0.39 , respectively.

\subsection{The selection of driving factors and quantitative recognition method}

\subsubsection{Driving factors}

FFE is the result of the interactions and influence between regional indigenous factors and external driving factors. The state of FFE is determined by the power of driving forces. Topography, climate, hydrology, and farmland resources are the basic natural factors that provide support for FFE. Urbanization, industrialization, agricultural modernization, and regional development policies are the external factors that give impetus to the FFE by boosting the flow of urban-rural elements and industrial interaction (Figure 2).

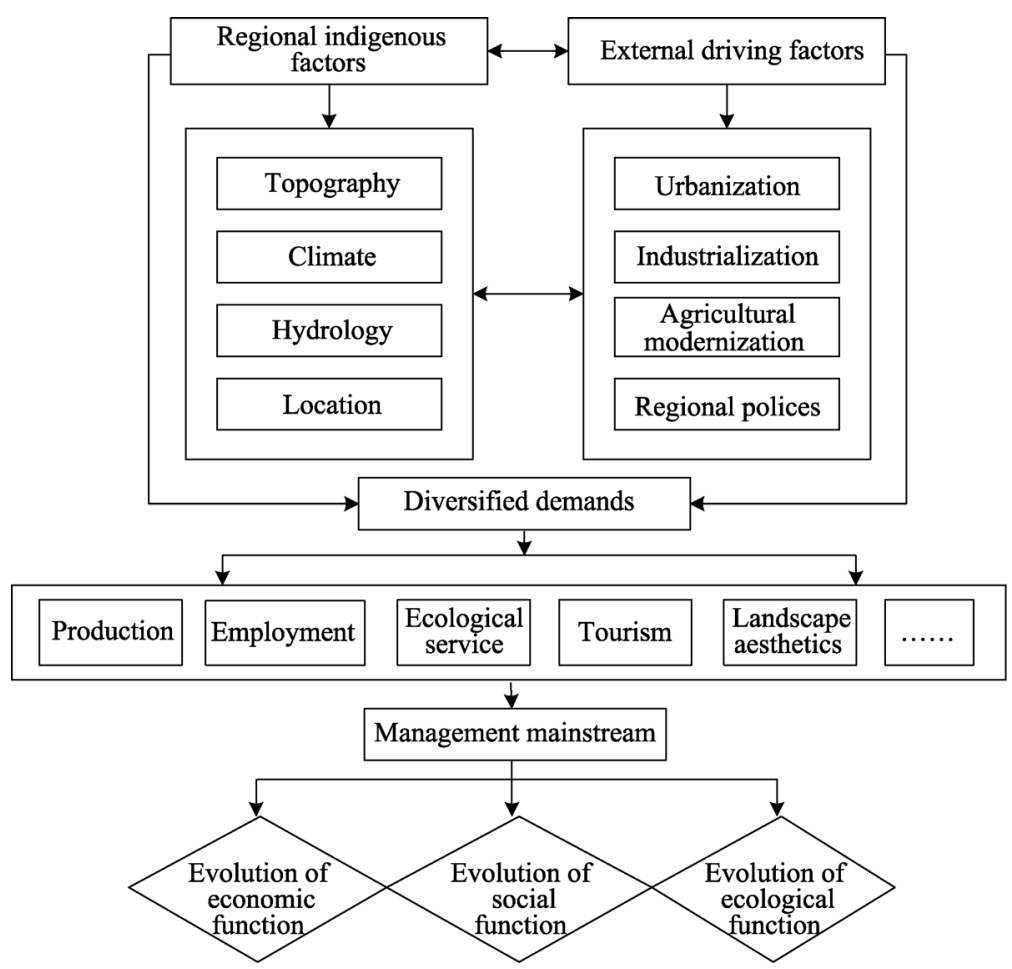

Figure 2 The conceptual framework for the dynamic mechanisms of FFE

Regional indigenous factors: (1) Natural conditions, which are regarded as the prerequisite of farmland use, fundamentally affect agricultural production and resource supply capacity. In spite of the fact that the change in natural factors is weak and not very obvious over the short term, farmland productivity varies widely because of the large span from the south to the north and clear regional differences of precipitation in the HHHP. Accordingly, elevation, average annual precipitation and distance from major rivers were selected as the 
major natural driving factors. (2) Transportation accessibility is an effective indicator to estimate location advantage. Hence, distances to national, provincial, and county roads were used to provide a comprehensive estimation of regional transportation accessibility.

External driving factors: (1) It is universally acknowledged that establishing a multidimensional evaluation index system of urbanization covering the economy, society, and space (land) is a difficult task at county level due to the overwhelming obstacle of collecting socio-economic statistical data. Considering the powerful effects of urbanization on surrounding regions, this paper first established an evaluation index system for urbanization level at the level of the prefecture (Table 2). In order to avoid repetition in indices, indices related to industrialization were not involved in the economic urbanization evaluation index system. Next, prefecture-level cities were classified into five levels according to their comprehensive influence (Figure 3). Then, the scores associated with their influence received from corresponding core cities were calculated using a linear attenuation model that was based on the influential sphere of core cities designated by the Weighted Voronoi Method (Gu et al., 2014). (2) The number of industrial enterprises per unit land area and percentage of industrial added value in GDP at county level was used to indicate the industrialization level. (3) The increase in yield-increasing and labor-saving inputs triggered by agricultural modernization boosted farmland productivity and the de-agriculturalization transfer of rural labor. Simultaneously, excessive fertilizer inputs can cause severe agriculture non-point source pollution and threaten farmland ecosystems. (4) Regional development policies regarding farmland protection, balancing urban and rural construction land, grain purchasing and storage, water-saving agriculture and environmental agriculture, exerted limitation or guidance on FFE.

Table 2 The evaluation index system for urbanization level

\begin{tabular}{|c|c|c|c|c|}
\hline Criterion & Index & Unit & Direction & Weight $^{1)}$ \\
\hline \multirow{4}{*}{$\begin{array}{l}\text { Economic } \\
\text { urbanization }\end{array}$} & GDP per unit land area in municipal districts & 10,000 yuan $/ \mathrm{km}^{2}$ & + & 0.12 \\
\hline & GDP per capita & yuan/person & + & 0.11 \\
\hline & Percentage of tertiary industry added value in GDP & $\%$ & + & 0.07 \\
\hline & $\begin{array}{l}\text { Total retail sales of consumer goods per capita in } \\
\text { municipal districts }\end{array}$ & yuan/person & + & 0.03 \\
\hline \multirow{3}{*}{$\begin{array}{l}\text { Social } \\
\text { urbanization }\end{array}$} & Fixed assets investment per capita & yuan/person & + & 0.05 \\
\hline & $\begin{array}{l}\text { The number of beds in medical and health institu- } \\
\text { tions per million people }\end{array}$ & - & + & 0.08 \\
\hline & The number of buses per million people & - & + & 0.04 \\
\hline \multirow{4}{*}{$\begin{array}{l}\text { Land } \\
\text { urbanization }\end{array}$} & Local fiscal expenditure per capita & yuan/person & + & 0.10 \\
\hline & Proportion of built-up area & $\%$ & + & 0.13 \\
\hline & Built-up area per capita & $\mathrm{m}^{2} /$ person & + & 0.13 \\
\hline & Urban road area per capita in municipal districts & $\mathrm{m}^{2} /$ person & + & 0.12 \\
\hline
\end{tabular}

Note: 1) The method combining entropy weighting and multiple correlation coefficients weighting was used to determine indices' weights.

Farmland management mainstream: As the management mainstream of farmland, rural population has the dual status of producer and customer. The proportion of the rural population and the proportion of the population with an educational level above junior middle school in the total population were adopted to show the peculiarities of farmland management mainstream from the perspective of quantity and quality. 


\subsubsection{Spatial econometric} regression analysis

In light of the relevance of the sub-function indices for different regions, the use of a spatial econometric model to explore their influencing factors can make up for the disadvantages of a traditional econometric model, because it explores the spatial correlation among explanatory variables or random error terms (Anselin, 1998). There are many kinds of spatial econometric models. Spatial constant coefficient models, including a Spatial Lag Model (SLM) and a Spatial Error Model (SEM) (Fang et al., 2013), were chosen for this study.

\section{Results}

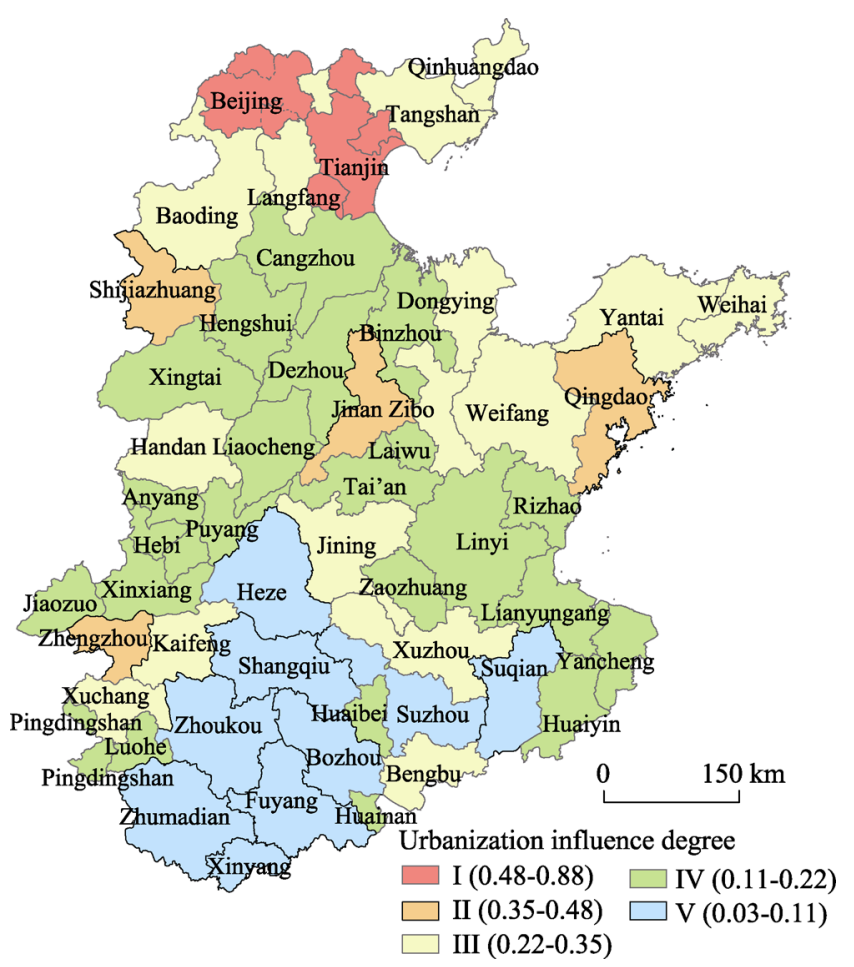

Figure 3 Urbanization influence classification for cities in the HHHP

\subsection{Spatio-temporal characteristics of FFE}

\subsubsection{Spatio-temporal patterns of FFE}

Spatio-temporal patterns of economic function evolution: Economic function in the HHHP generally weakened during 1990-2010 and showed prominent spatial differentiation between growing areas and declining areas. Economic function generally increased and the rate of change was normally distributed. The regions of growth mainly concentrated in the central part of Hebei, eastern Henan, and western Shandong, while decreasing areas were mostly distributed in and around the Beijing-Tianjin metropolitan area, the Yantai-Weihai urban area, and Jinan (Figures 4a and 5a). Skewness and Kurtosis clearly increased due to the sharp increase of economic function in some counties during 2000-2010 (Figures $4 \mathrm{~b}$ and $5 \mathrm{~b})$. Compared to the last period, the number of growing counties significantly reduced, and nearly $92.06 \%$ of the counties experienced a decline in economic function, while the remaining 27 increasing counties mainly scattered around the southern part of Hebei and Henan. During 1990-2010, the growth areas were mainly located in the central and southern part of Hebei and eastern Henan (Figures $4 \mathrm{c}$ and $5 \mathrm{c}$ ). The last 20 years have witnessed a continuous decline in areas surrounding Beijing and Tianjin, Yantai-Weihai, and Jinan, which were deeply affected by urbanization and industrialization. Meanwhile, agricultural production efficiency was low in northern Anhui Province because of the larger proportion of traditional agriculture and the smaller fraction of high efficiency facility agriculture and leisure agriculture.

Spatio-temporal patterns of farmland social function evolution: $51.18 \%$ of the counties 
experienced a clear decrease in social function, which were mainly distributed around the northern Anhui and the Beijing-Tianjin metropolitan area (Figures $4 \mathrm{~d}$ and 5d). Counties that experienced an enhancement in social function, the number of which was 83, were mostly concentrated in the west of Cangzhou, Yantai, Weihai, Jining, Linyi, and Weifang. During 2000-2010, the number of growing counties dropped by 10\%, while traditional growth areas, including Weifang, Yantai, and the northern part of Zhengzhou, still maintained a rather strong growth trend. Some regions with extremely high growth rates gave rise to the significant peak and fat tail of the density map. The spatial patterns of social function change during 1990-2010 (Figure 4f) was roughly the same as that during 2000-2010; meanwhile, a small set of cities including Dezhou, Cangzhou, and Hengshui declined somewhat during 2000-2010. The social function index change rate for $89.12 \%$ of the counties ranged from $-35 \%$ to $35 \%$, and Skewness and Kurtosis fell compared to 2000-2010 (Figure 5f). The developed rural areas surrounding Beijing and Tianjin were dominated by industry and commerce. The rapid development of rural industry and tourism, coupling with scarce
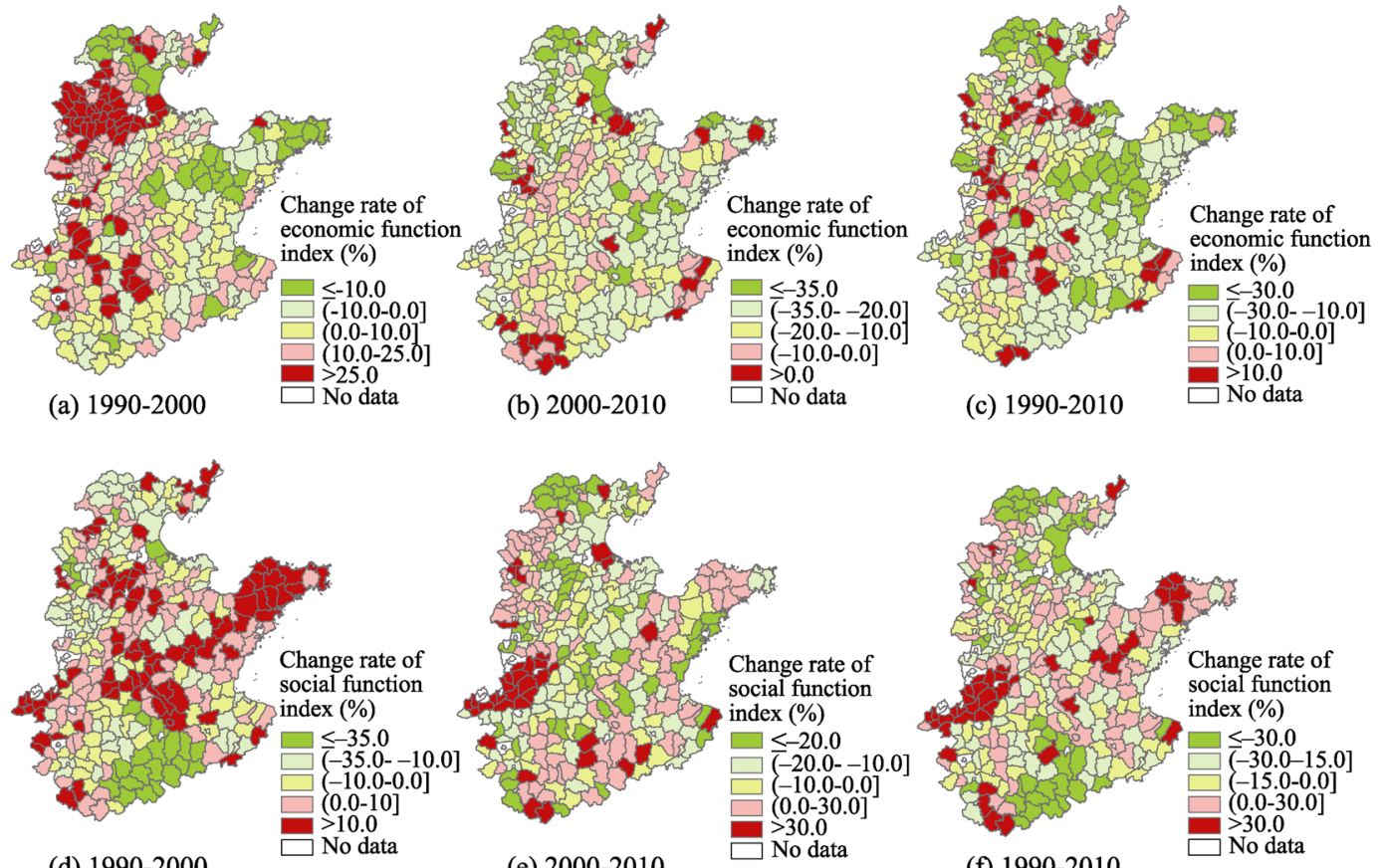

(e) $2000-2010$

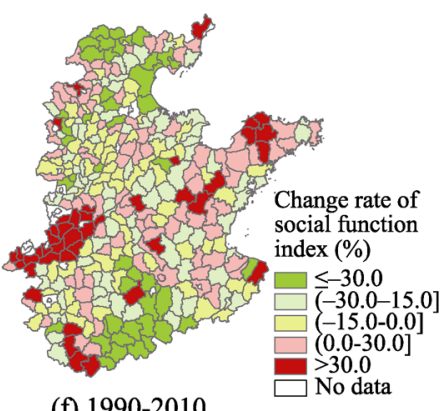

(f) 1990-2010

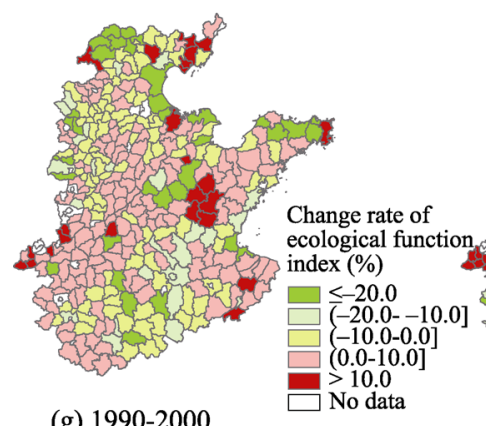

(g) $1990-2000$

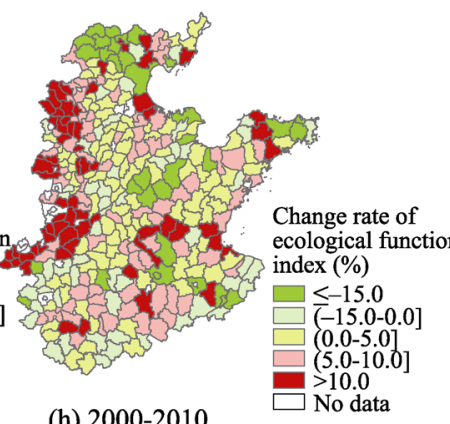

(h) $2000-2010$

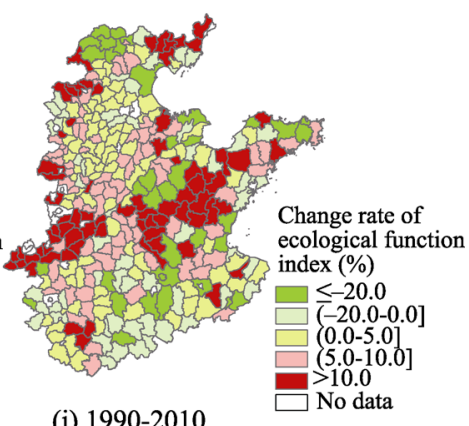

(i) $1990-2010$

Figure 4 The spatial patterns of the change rate of FF in the HHHP during 1990-2010 
farmland resources and the high proportion of non-agricultural employment, contributed to the continuous decline of employment carrying capacity. Rural areas with high population density, high population growth rate, and lagged non-agricultural industries underwent reductions in their social function indices due to urbanization and industrialization, compared to their high baseline of index values. Where there were low levels of agricultural industrialization or imperfect industrialization, rural populations in Xinxiang, Jiaozuo, Hebi, Anyang, Zhoukou, and Zhumadian in Henan were still highly dependent on farmland. Yantai, Weihai, and their adjacent hilly areas in east Shandong Peninsula were characterized by large farming areas per capita and high proportion of the cash crop. Relatively-developed modern agriculture, urban agriculture, and ecological agriculture jointly affected the employment choices of the rural population in these areas to a great degree.
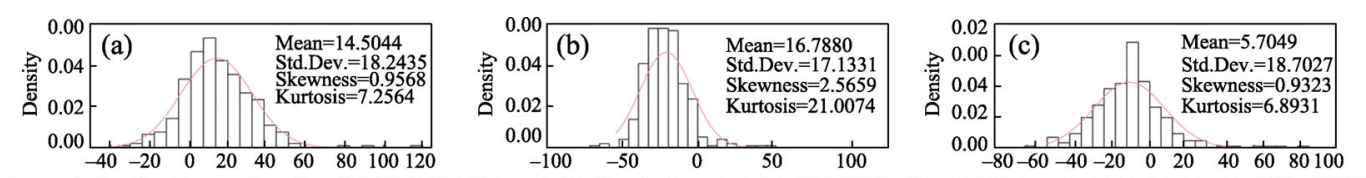

Economic function change rate during 1990-2000 (\%) Economic function change rate during 2000-2010 (\%) Economic function change rate during $1990-2010$ (\%)

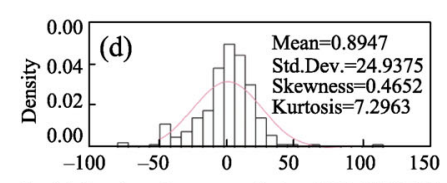

Social function change rate during 1990-2000 (\%)
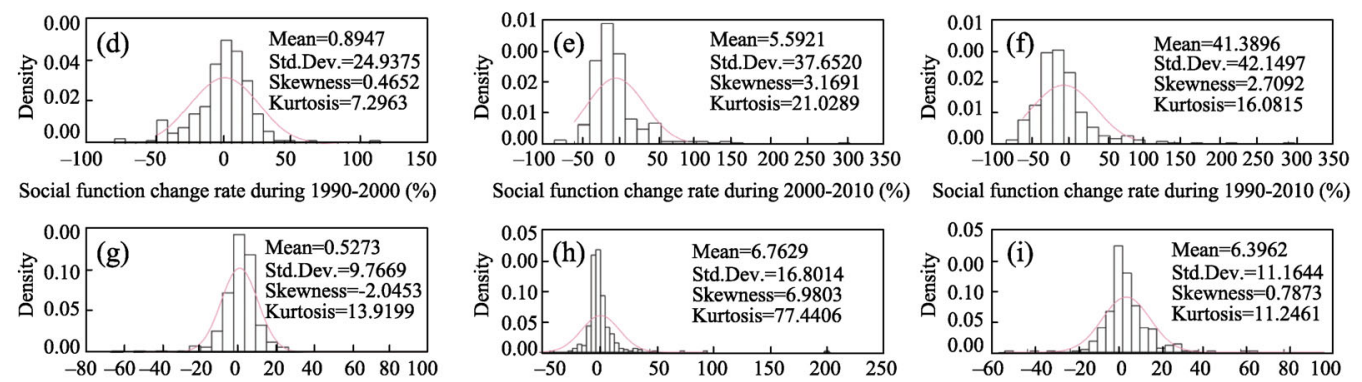

Social function change rate during 1990-2010 (\%)

Ecological function change rate during 1990-2000 (\%) Ecological function change rate during 2000-2010 (\%) Ecological function change rate during 1990-2010 (\%)

Figure 5 The density graphic of the change rate of FF index in the HHHP

Spatio-temporal patterns of ecological function evolution: Ecological function evolution was characterized by a larger fluctuation and clear differences in spatial patterns between different periods. Of all the counties, $47.35 \%$ experienced ecological function declines, especially around Beijing-Tianjin, the east of Shandong, and the north of Anhui (Figures $4 \mathrm{~g}$ and $5 \mathrm{~g}$ ). Growth areas mainly concentrated in the north and south of Henan, and the east and west of Shandong. The sharp increase in farmland area of most counties in Yantai, Weihai, and Qingdao showed that farmland played a significant role in environmental conservation. Abundant farmland and lower fertilizer and pesticide inputs jointly contributed to the increase in ecological function. Change rates of ecological function varied between $-50 \%$ and 50\% during 2000-2010 (Figures $4 \mathrm{~h}$ and 5h), while the Kurtosis reached 77.44 due to the outliers, which caused the high peak and fat tail on the density map. During this period, the growth areas were mainly distributed in western Hebei, northern Henan, and northern Anhui. During 1990-2010, the core areas of growth centered around northern Henan and central Shandong, and areas around Beijing, Tianjin, and Jinan were the primary decreasing areas.

4.1.2 Spatio-temporal characteristics of the coupling effect among economic, social, and ecological functions

The "economy-society-ecology" composite system of farmland is open, dynamic, and complex, and if one component is out of order it would result in the decline of system coordina- 
tion and cause its deviation from the given targets. (1) Economic function was closely associated with natural property and human management activities. Productivity can be modified by the input of various elements and changes in utilization. Driven by the multiple goals of guaranteeing food security, increasing farmers' income and promoting grain production, pesticides, fertilizers, and agricultural machinery certainly will increase if agricultural technology is improved. Moderate pesticide, fertilizer, and other yield-increasing inputs will either enhance the farmland productivity or prevent farmland ecosystem degradation. Increasing labor-saving inputs directly promote agricultural production and free more rural labor from cultivation affairs, as well weaken traditional labor intensive agriculture. (2) Farming is the last guarantee for peasants to get employment. As such, it is farmers who realize the economic value of farmland. Modern agricultural practices, such as urban and ecological agriculture, lead to localized employment and directly motivate the efficient utilization and intensive management of farmland. Meanwhile, if farmland carried excessive population, it would initiate agricultural involution, which is against the promotion of agricultural productivity and rural economic development. Similarly, the dual effects of population growth and farmland decreasing jointly exert pressure on existing farmland. (3) A favorable farmland environment is a basic condition and support for maximizing its socio-economic functions. On the contrary, environmental damages, such as soil salinization, soil erosion, heavy metal pollution, and agricultural non-point source pollution will constrain agricultural production.

(a) 1990

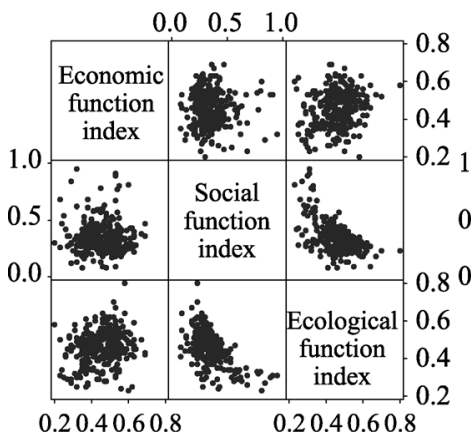

(b) 2000

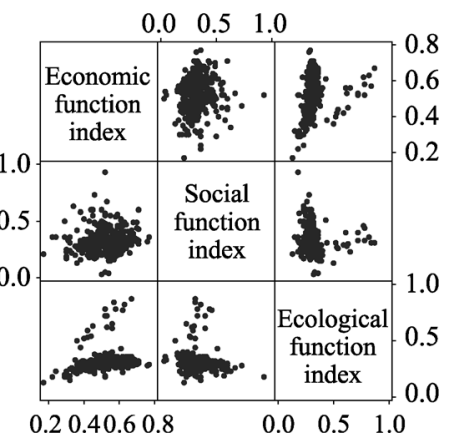

(c) 2010

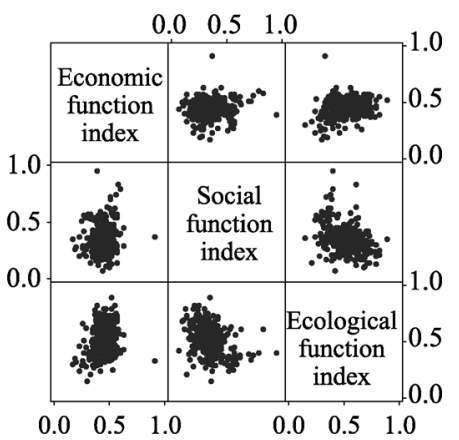

Figure 6 The matrix scatter diagram of farmland economic, social, and ecological function indices in the HHHP in 1990,2000 and 2010

The synergistic evolution of the population, land use, and industry inevitably coincides with the changing interactions among farmland economic, social, and ecological sub-systems (Figure 6). The results from the coupling degree model showed that there was clear spatial variation in coupling degree (Figures $7 \mathrm{a}, 7 \mathrm{~b}$ and $7 \mathrm{c}$ ). (1) Areas with a coupling degree greater than 0.6 were in high numbers, widely distributed, and concentrated. Affected by urbanization and industrialization, traditional agriculture contributed less to national economic growth and rural household income. The nearly equivalent de-agriculturalization rates of land, population, and industry made a smaller difference among farmland sub-function indices for most counties across different periods, thus creating the high coupling degree. (2) Areas with a low coupling index were mainly concentrated around Beijing, Tianjin, Jinan, Yantai, and Weihai. Compared to 1990, the coupling degrees in 2000 and 2010 were relatively lower. The decline of primary industry and the rise of industry and commerce jointly triggered the transition in employment structure. Farmland sub-functions 
(a) 1990

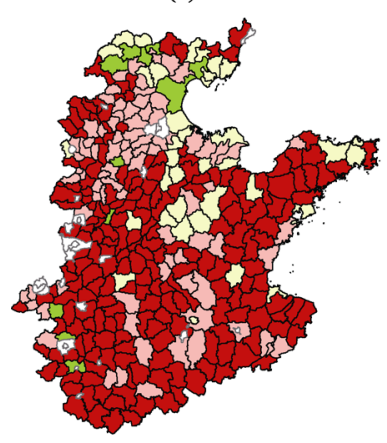

Coupling degree $[0.0-0.4)$ Low-level coupling

(d) 1990

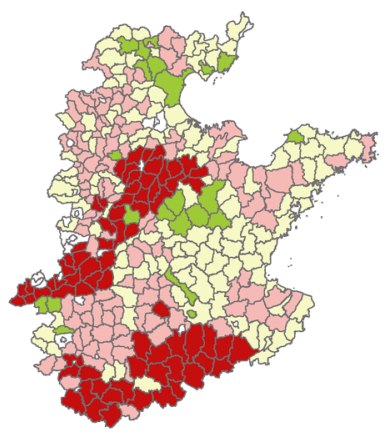

Coupling coordination degree $\square[0.0-0.4)$ Slightly coordinated (b) 2000

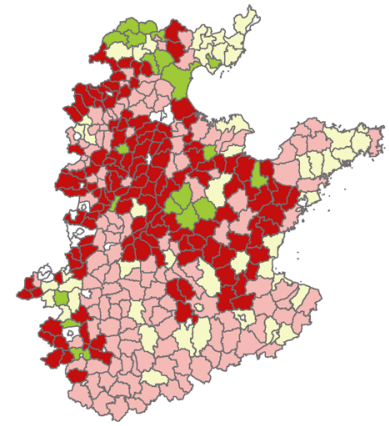

[0.4-0.6) Antagonistic [0.6-0.8) Running-in

(e) 2000

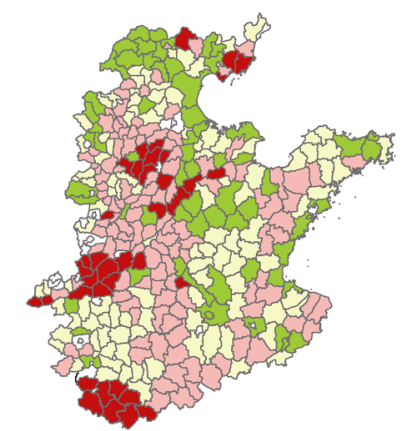

[0.4-0.6) Generally coordinated [0.6-0.8) Moderately coordinated (c) 2010

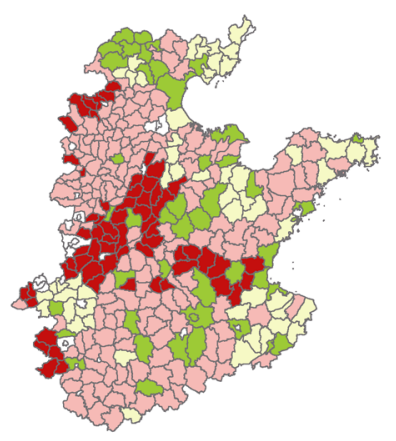

[0.8-1.0) Mature

No data

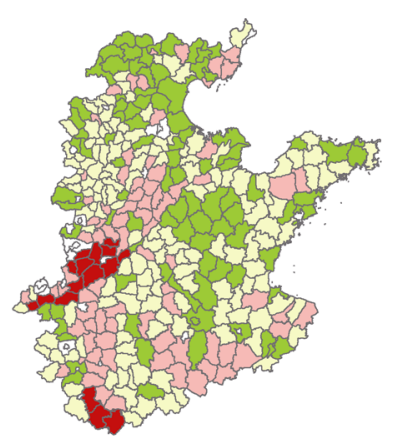

[0.8-1.0] Extremely coordinated No data $0 \quad 200 \mathrm{~km}$

Figure 7 The spatial distribution of the coupling and coordination degrees for farmland economic, social, and ecological functions in the HHHP in 1990, 2000, and 2010

diverged as farmland was continuously encroached by construction land, which caused the coupling degree decrease. (3) From the viewpoint of temporal evolution, the coupling degree of the sub-functions shown a general downward trend, especially in the areas surrounding Beijing and Tianjin. Areas with high coupling degree shrank as a result of the unbalanced performance of the sub-functions.

In order to conduct further research on the coupling and coordination relationships between the three sub-functions mentioned above, a coupling coordination model was adopted to comprehensively analyze the coordination level. The results showed that: (1) Compared to coupling degree, areas with corresponding value intervals shrank dramatically and the low value zones expanded. (2) Counties with a high coupling coordination degree were mainly located in Dezhou, Hengshui, southern Henan, northern Anhui, and other undeveloped areas dominated by traditional agriculture. In general, most counties in the Shandong Peninsula underwent sustainable economic, social, and ecological development through the transformation and upgrade of traditional agriculture, forming an advanced coupling morphology rather than underdeveloped areas with high dependence on farmland for socio-economic development. (3) When it comes to dynamic evolution, initial areas with high values gradually shrank and areas with low values expanded around the original center. The farmland sub-functions of 
economy, society, and ecology gradually were differentiated by de-agriculturalization of population, land and industry. Abundant farmland resources and agricultural modernization enhanced economic function. The migration of surplus rural labor and the decline in people engaging in agriculture brought the farmland socio-economic function index down, and resulted in the decline of coupling coordination degree.

\subsection{The dynamic mechanisms of FFE}

The economic, social, and ecological function indices, along with the explanatory variables, were imported into GeoDa and analyzed using Ordinary Least Squares (OLS), SLM, and SEM to explore the driving factors of FFE. Model selection was based on the results of a spatial correlation test. If Moran's I and LR-LM Lag were significant, the LR-LM Error was not significant, and the LM-Lag was larger than the LM-Error, SLM was chosen; otherwise, SEM was chosen. Log L likelihood (Log L), Likelihood Ratio (LR), the Akaike information criterion (AIC), and the Schwartz Criterion (SC) are usually taken into consideration in the process of model selection. The larger the Log L is, and the smaller the AIC and SC are, the better the fit (Liu and Long, 2016). These indicators were also used to compare OLS, SLM, and SEM, and the largest Log L represents the most appropriate choice. According to the results (Table 3), SEM was more suitable for explaining economic and ecological function evolution, and SLM was more appropriate for social function evolution.

The spatial econometric analysis results at the county level indicated that regional indigenous factors and external driving factors jointly determined the direction and extent of FFE. The specific dynamic mechanisms of economic, social, and ecological function evolution are as follows (Table 4).

Table 3 Results of spatial correlation tests for FFE in the HHHP

\begin{tabular}{lccc}
\hline \multicolumn{1}{c}{ Spatial dependence test } & Economic function & Social function & Ecological function \\
\hline Moran's I (error) & $9.8575^{* * *}$ & $6.7193^{* * *}$ & $9.2617^{* * *}$ \\
Lagrange Multiplier (lag) & $38.4304^{* * *}$ & $28.1586^{* * *}$ & $19.1501^{* * * *}$ \\
Robust LM (lag) & $1.7955^{*}$ & $5.3022^{* *}$ & 2.3325 \\
Lagrange Multiplier (error) & $54.1750^{* * *}$ & $23.0057^{* * *}$ & $47.2461^{* * *}$ \\
Robust LM (error) & $17.5401^{* * *}$ & 0.1493 & $30.4286^{* * *}$ \\
Lagrange Multiplier (SARMA) & $55.9706^{* * *}$ & $28.3079^{* * *}$ & $49.5786^{* * *}$ \\
\hline
\end{tabular}

Note: *: Significant correlation at the $10 \%$ level; **: Significant correlation at the $5 \%$ level; ***: Significant correlation at the $1 \%$ level

Economic function had a clear positive correlation with traffic accessibility, the number of industrial enterprises per unit land area, percentage of industrial added value in GDP, and urbanization influence index at a significance level of $1 \%$, as well as average annual precipitation at a significance level of 5\%. Additionally, it had a negative correlation with elevation at a significance level of $10 \%$, and there was no significant correlation with distance from major rivers, the proportion of rural population, and education level. (1) Compared to the plain areas, hilly areas were characterized by scarce and scattered farmland, high levels of difficulty for automated cultivation, and expensive irrigation costs, which severely restricted agricultural management and reduced the efficiency of farmland utilization. For instance, Fangshan and Shunyi counties, which are located around Beijing, developed a prosperous valley economy, and planting became a minor choice for farmers. Specialized tourism and 
Table 4 The spatial regression analysis results for FFE and influence factors in the HHHP

\begin{tabular}{|c|c|c|c|c|c|c|c|c|c|}
\hline \multirow{2}{*}{ Factors } & \multicolumn{3}{|c|}{ Economic function } & \multicolumn{3}{|c|}{ Social function } & \multicolumn{3}{|c|}{ Ecological function } \\
\hline & OLS & SLM & SEM & OLS & SLM & SEM & OLS & SLM & SEM \\
\hline \multirow[t]{2}{*}{ Elevation } & -0.13 & -0.18 & -0.31 & 0.13 & -0.06 & -0.05 & -0.49 & -0.42 & -0.58 \\
\hline & $* *$ & $* * *$ & $*$ & & & & $* * *$ & $* * *$ & $* * *$ \\
\hline \multirow{2}{*}{$\begin{array}{l}\text { Distance from } \\
\text { major rivers }\end{array}$} & 0.04 & 0.03 & -0.23 & -0.06 & -0.01 & 0.11 & 0.25 & 0.12 & 0.06 \\
\hline & & & & & & & $* * *$ & $* *$ & $* *$ \\
\hline \multirow{2}{*}{ Precipitation } & 0.07 & 0.05 & 0.27 & 0.07 & 0.05 & 0.30 & 0.006 & 0.01 & 0.20 \\
\hline & $* *$ & $* *$ & $* *$ & & & & $* *$ & $* *$ & $* *$ \\
\hline Traffic & -0.13 & -0.13 & -0.13 & -0.05 & -0.06 & -0.06 & - & - & - \\
\hline accessibility & $* * *$ & $* * *$ & $* * *$ & $* *$ & $* *$ & $* *$ & & & \\
\hline \multicolumn{10}{|l|}{ The number of } \\
\hline enterprises per & $* *$ & $*$ & $* * *$ & $* *$ & ** & $* * *$ & $* *$ & $* *$ & $* * *$ \\
\hline unit land area & & & & & & & & & \\
\hline \multirow{2}{*}{$\begin{array}{l}\text { Percentage of } \\
\text { industrial added } \\
\text { value in GDP }\end{array}$} & -0.22 & -0.14 & -0.12 & -0.09 & -0.11 & & -0.24 & -0.21 & -0.20 \\
\hline & $* *$ & $*$ & $* * *$ & $* * *$ & $* * *$ & $-0.13+4$ & $* * *$ & $* *$ & $* * *$ \\
\hline \multirow{2}{*}{$\begin{array}{l}\text { Proportion of } \\
\text { rural population }\end{array}$} & 0.15 & 0.14 & 0.17 & 0.20 & 0.19 & 0.20 & -0.04 & -0.03 & -0.02 \\
\hline & & & & $* * *$ & $* * *$ & $* * *$ & $* *$ & $* *$ & $* *$ \\
\hline \multirow{2}{*}{$\begin{array}{c}\text { Education } \\
\text { level }\end{array}$} & 0.002 & 0.001 & 0.001 & -0.003 & -0.002 & -0.002 & -0.001 & -0.01 & -0.01 \\
\hline & & & & $* * *$ & $* * *$ & $* * *$ & & & \\
\hline \multirow{2}{*}{$\begin{array}{l}\text { Urbanization } \\
\text { influence index }\end{array}$} & -0.15 & -0.119 & -0.11 & -0.076 & -0.06 & -0.06 & -0.07 & -0.06 & -0.09 \\
\hline & $* * *$ & $* * *$ & $* * *$ & $* *$ & $* *$ & $* * *$ & $* * *$ & $* *$ & $* *$ \\
\hline \multirow[t]{2}{*}{ W-Y } & & 0.71 & & & 0.67 & & & 0.61 & \\
\hline & & $* * *$ & & & $* * *$ & & & $* * *$ & \\
\hline \multirow[t]{2}{*}{ Lambda } & & & 0.88 & & & 0.81 & & & 0.84 \\
\hline & & & $* * *$ & & & $* * *$ & & & $* * *$ \\
\hline$R^{2}$ & 0.19 & 0.33 & 0.41 & 0.23 & 0.34 & 0.36 & 0.42 & 0.49 & 0.55 \\
\hline Log-L & 210.86 & 233.29 & 245.89 & 258.16 & 275.32 & 277.62 & 241.30 & 255.81 & 267.81 \\
\hline AIC & -401.71 & -444.58 & -471.78 & -496.32 & -528.64 & -535.23 & -462.61 & -489.62 & -515.62 \\
\hline $\mathrm{SC}$ & -365.16 & -404.37 & -435.22 & -459.76 & -488.43 & -498.67 & -426.05 & -449.40 & -479.06 \\
\hline
\end{tabular}

Note: *: Significant correlation at the $10 \%$ level; **: Significant correlation at the $5 \%$ level; ***: Significant correlation at the $1 \%$ level

other non-agricultural industries relying on the location advantage of metropolitan suburbs and specialized resources of mountain areas, have become the main source of farmers' income. (2) Theoretically, precipitation is positively correlated with farmland production capacity, but the average annual precipitation showed a decreasing trend from south to north, and from the coastal areas to inland areas. Due to the export-oriented economy, coastal areas had higher levels of urbanization and industrialization, which caused agriculture weaken in the national and rural household economies. (3) With the implementation of high standard basic farmland construction, distance from major rivers was no longer a constraint for field irrigation due to the improvement in irrigation facilities. (4) Favorable location nearby regional central cities was a prerequisite for economic growth. The boom in non-agricultural industries was motivated by the transfer of capital, information, technology and, talents from metropolitan regions to the surrounding areas. (5) Impacts of industrialization imposed on economic function were summarized into two points. On the one hand, the rapid increase in the proportion of industrial outputs in GDP reduced the proportion of agricultural outputs. 
On the other hand, so much high quality farmland was occupied that the economic output declined. (6) The increasing frequency of urban and rural interactions, the accelerated flows of economic elements, and the rapid development of non-agricultural industries were attributed to changes in industry structure, and manifested as an increase in urbanization rate. The increasing demand for residential land, public services, and infrastructure induced by population growth in urban areas, resulted in the loss of farmland and a decline in economic function. It should be noted that economic function of areas oriented around traditional agriculture was enhanced because of the promotion of agricultural industrialization and modernization, but across the entire HHHP it generally declined.

Social function evolution did not have a significant correlation with natural factors, but it was negatively correlated with traffic accessibility, the number of industrial enterprises per unit land area, and the urbanization influence index at a significance level of 5\%, while percentage of industrial added value in GDP and education level were correlated at a significance level of $1 \%$. Additionally, social function had a strong positive correlation with the proportion of rural population at a significance level of 1\%. 1) Well-equipped transportation networks in favor of rural-urban migration, promoted part-time farming and employment de-agriculturalization of surplus rural labor. 2) In the process of industrialization and urbanization, working in cites turns to be the best choice for rural middle-aged labor driven by increasing labor demand of industry development. Moreover, the increasing number of land-deprived residents who were compelled to leave agriculture became the primary reason for the weakening of farmland social function. 3) Farmland management was still the main way of maintaining minimum subsistence levels and resisting social risks due to the large and dense rural population in the HHHP. Human resources, whose capacity of getting employment was restrained by education level, were the most dynamic factor in rural development. Well-educated farmers may more easily adapt to multiple employment choices and reduce their dependence on farmland.

Ecological function evolution had a strong negative correlation with elevation. The number of industrial enterprises per unit land area, and the percentage of industrial added value in GDP at a significance level of $1 \%$, and the proportion of rural population and the urbanization influence index were significant at the $5 \%$ level, but there was a positive correlation with distance from main rivers and average annual precipitation at a significance level of 5\%. 1) Scarce farmland, together with land development in hilly areas resulted in the decline of the proportion of ecological farmland. 2) Extensive economic growth, excessive resource exploitation, and poor management jointly caused disorderly development and soil and water pollution, which further led to the sharp drop in total farmland area and the degeneration of soil quality. Meanwhile, farmland ecosystems were further damaged by excessive fertilizer and pesticide inputs that for increasing grain yield. 3) Shrinking farmland areas and an increasing rural population imposed more pressure on farmland.

\section{Discussion and conclusions}

\subsection{Discussion}

(1) All sub-functions of farmland gradually declined due to urbanization and industrialization in the HHHP, while the value they possess was continuously improved in virtue of 
resource scarcity. Hence, a comprehensive understanding of FFE and the declining trend of some sub-functions is critical to achieving modern agriculture and upgrading traditional agriculture, as well as promoting endogenous development and increasing the efficiency of agricultural production.

(2) Multifunctional farmland use and management should be aimed at people's diverse demand at given socio-economic development context. Dominant function transfer from economic and social oriented at a low socio-economic level to ecological and cultural oriented, while other derivative functions appear in company with the flourished non-agricultural industries. The decline of economic function is mainly attributed to construction land encroachment and the decreased status of agriculture in both national and household economy. More importantly, countermeasures such as improving basic mechanisms of land supply and planning, landscape design, and ecological design should be implemented to enhance farmland ecological function.

(3) In view of the existing obvious regional difference of FFE, distinguished and diversified multifunctional farmland use and management policies are needed to be proposed for optimizing the layout of farmland functions. Over emphasizing the requisition-compensation balance will result in superficial and shoddy balance of farmland area. In order to internalize the cost of farmland loss and enhance farmland ecological protection, it is necessary to develop ecological agriculture from the perspective of regional eco-environmental security. As for underdeveloped rural areas, advocating modern agriculture is an appropriate choice for promoting economic benefits and enhancing the capacity of labor absorption.

(4) Limited by the complexity of farmland system, there is still not a generalized and perfect FF classification system. A widely accepted classification system, which can provide the theoretical basis for FF assessment, urgently needs to be established. Current research on FFE mainly focuses on the macro scale rather than micro scale, such as the village and household. Therefore, studies of FFE from the micro perspective will be the emphasis of future research.

\subsection{Conclusions}

The spatio-temporal patterns of FFE had clear regional differences in the HHHP during 1990-2010. Economic function generally tended to decline, but was enhanced in underdeveloped areas that dominated by agriculture. Counties surrounding the Beijing and Tianjin metropolitan circle, Yantai, Weihai, and Jinan experienced a dramatic decline in economic function. However, farmland in counties around the north of Anhui failed to contribute more to economic growth on account of the lagging agricultural industrialization and modernization. $60.29 \%$ of the counties have experienced a decline in social function. And the increasing counties mostly concentrated in the north part of Zhengzhou and Dezhou, and the west part of Cangzhou, Yantai, and Weihai. The sharply decreasing areas of ecological function mainly gathered around Beijing, Tianjin and Jinan, while the areas of growth mostly concentrated in northern Henan and central Shandong.

The spatio-temporal pattern of coupling and coordination degree shows obvious spatial heterogeneity in the HHHP during 1990-2010, and the decoupling of sub-functions was getting prominent. The coupling and coordination degree of developed areas were lower than that of underdeveloped areas, and the evolution of social function and ecological function lagged behind economic function. Areas with high coupling and coordination degree were 
mainly distributed in underdeveloped rural areas with lagging population and industrial transitions, as well as rural areas, presenting balanced economic, social, and ecological performance.

Farmland multifunctional evolution was influenced by both regional indigenous factors and external driving factors. The direction and intensity of FFE were determined by population and industrial transitions in the course of urbanization and industrialization. Meanwhile, FFE was sustained by regional indigenous factors and promoted by rural development mainstream, who altered the behaviors of farmland use through employment option and diverse management modes.

\section{References}

Anselin L, 1988. Spatial Econometrics: Methods and Models. Dordrecht: Kluwer Academic Publishers.

Chen L, Hao J, Wang F et al., 2016. Carbon sequestration function of cultivated land use system based on the carbon cycle for the Huang-Huai-Hai Plain. Resources Science, 38(6): 1039-1053. (in Chinese)

Evans L T, Fischer R A, 1999. Yield potential: Its definition, measurement, and significance. Crop Science, 39(6): 1544-1551.

Fang Y, Xie W, Lin Z, 2013. A spatial econometric analysis of impact of ICT on service innovation: Based on analysis of 21 cities in Guangdong Province. Acta Geographica Sinica, 68(8): 1119-1130. (in Chinese)

Fleskens L, Duarte F, Eicher I, 2009. A conceptual framework for the assessment of multiple functions of agro-ecosystems: A case study of Trás-os-Montes olive groves. Journal of Rural Studies, 25(1): 141-155.

Gu J, Zhou T, Guo L, 2014. Urban influence regions and spatial relation of Beijing-Tianjin-Hebei Region based on Weighted Voronoi Diagram and Breakpoint Theory. Geography and Geo-information Science, 30(1): 65-69. (in Chinese)

$\mathrm{Hu}$ R, Qiu D, Xie D et al., 2014. Assessing the real value of farmland in China. Journal of Mountain Science, 11(5): 1218-1230.

Jiang G, Zhang F, Kong X et al., 2011. The different levels and the protection of multi-functions of cultivated land. China Land Sciences, (8): 42-47. (in Chinese)

Jongeneel R, Polman N, Slangen L, 2008. Why are Dutch farmers going multifunctional? Land Use Policy, 25(1): 81-94.

Ke X, Li H, Liu R et al., 2016. Research on the spatial matching pattern of cultivated land landscape recreation function and accessibility in Wuhan. Resources and Environment in the Yangtze Basin, 25(5): 751-760. (in Chinese)

Li G, Han L, 2007. The social function and compensation basis of rural land. Shandong Social Sciences, (1): 73-75. (in Chinese)

Li H, Wu Y, Huang X et al., 2017. Spatial-temporal evolution and classification of marginalization of cultivated land in the process of urbanization. Habitat International, 61: 1-8.

Liu H, Zhang Y, Zheng W, 2011. Evaluation on spatio-temporal development and interaction of intensive urban land use and urbanization: Case studies of the cities in the Bohai Rim Region. Geographical Research, 30(10): 1805-1817. (in Chinese)

Liu Y, Long H, 2016. Land use transitions and their dynamic mechanism in the Huang-Huai-Hai Plain. Acta Geographica Sinica, 71(4): 666-679. (in Chinese)

Liu Y, Long H, Li T et al., 2015. Land use transitions and their effects on water environment in Huang-Huai-Hai Plain, China. Land Use Policy, 47: 293-301.

Liu Y, Yang R, Long H et al., 2014. Implications of land-use change in rural China: A case study of Yucheng, Shandong province. Land Use Policy, 40: 111-118.

Long H, Liu Y, Li T et al., 2015. A primary study on ecological land use classification. Ecology and Environmental Sciences, 24(1): 1-7. (in Chinese)

Long H, Tu S, Ge D et al., 2016. The allocation and management of critical resources in rural China under restructuring: Problems and prospects. Journal of Rural Studies, 47: 392-412.

López-Ridaura S, Keulen H V, Ittersum M K V et al., 2005. Multiscale methodological framework to derive criteria and indicators for sustainability evaluation of peasant natural resource management systems. Environment, 
Development and Sustainability, 7(1): 51-69.

Luo C, Cai Y, 2016. The stage characteristics and spatial heterogeneity of cultivated land resource function evolution in agricultural producing areas of Hubei Province. Economic Geography, 36(3): 153-161. (in Chinese)

Matson P A, Parton W J, Power A G et al., 1997. Agricultural intensification and ecosystem properties. Science, 277(5325): 504-509.

Peng J, Liu Z, Liu Y et al., 2016. Assessment of farmland landscape multifunctionality at county level in Beijing-Tianjin-Hebei area. Acta Ecologica Sinica, 36(8): 2274-2285. (in Chinese)

Potschin M, Haines-Young R, 2008. Sustainability Impact Assessment of Land Use Changes. Berlin Heidelberg: Springer.

Rong H, Qiu D, Xie D et al., 2014. Assessing the real value of farmland in China. Journal of Mountain Science, 11(5): 1218-1230.

Sal A, García A, 2007. A comprehensive assessment of multifunctional agricultural land-use systems in Spain using a multi-dimensional evaluative model. Agriculture Ecosystems \& Environment, 120(1): 82-91.

Song G, E S, Xu S et al., 2013. Study on measurement of cultivated land ecosystem services evaluation in Bayan County. Journal of Northeast Agricultural University, 44(5): 126-131. (in Chinese)

Song X, 2013. Cultivated land transition in China: Dual deconstruction from spatial and functional perspectives [D]. Beijing: University of Chinese Academy of Sciences. (in Chinese)

Song X, 2017. Discussion on land use transition research framework. Acta Geographica Sinica, 72(3): 471-487. (in Chinese)

Song X, Huang Y, Wu Z et al., 2015. Does cultivated land function transition occur in China? Journal of Geographical Sciences, 25(7): 817-835.

Song X, Ouyang Z, 2012a. Connotation of multifunctional cultivated land and its implications for cultivated land protection. Progress in Geography, 31(7): 859-868. (in Chinese)

Song X, Ouyang Z, 2012b. Route of multifunctional cultivated land management in China. Journal of Natural Resources, 27(4): 540-551. (in Chinese)

Song X, Wu Z, Ouyang Z, 2014. Route of cultivated land transition research. Geographical Research, 33(3): 403-413. (in Chinese)

Sun X, Zou H, Xie G, 2007. Ecological functions and their values in Chinese cropland ecosystem. China Population, Resources and Environment, 17(4): 55-60.

Tan M, 2014. The transition of farmland production functions in metropolitan areas in China. Sustainability, 6(7): $4028-4041$.

Tian X, 2014. Study of multifunction cultivated land and its coupling mechanism with the socio-economic development in Beijing [D]. Beijing: China University of Geosciences. (in Chinese)

Todorova S, Ikova J, 2014. Multifunctional agriculture: Social and ecological impacts on the organic farms in Bulgaria. Procedia Economics \& Finance, 9(1): 310-320.

Ülo M, Wiggering H, Helming K, 2007. Multifunctional Land Use. Berlin Heidelberg: Springer.

Vereijken P, 2003. Transition to multifunctional land use and agriculture. NJAS-Wageningen Journal of Life Sciences, 50(2): 171-179.

Verma S R, 2006. Impact of agricultural mechanization on production, productivity, cropping intensity income generation and employment of labor. In: Status of Farm Mechanization in India. New Delhi: IARI, 133-153. (Accessed October 2017 at http://agricoop.nic.in/Farm\%20Mech.\%20PDF/05024-08.pdf)

Wu Z, Wei C, Ding S, 2013. Research on the social security function of cultivated land in a hilly-mountainous region. Resources Science, 35(4): 95-103. (in Chinese)

Yang R, Liu Y, Long H, 2015. The study on non-agricultural transformation co-evolution characteristics of "population-land-industry": Case study of the Bohai Rim in China. Geographical Research, 34(3): 475-486. (in Chinese)

Yang X, Tan M, 2014. Spatial differences and evolution of arable land functions in Beijing. Geographical Research, 33(6): 1106-1118. (in Chinese)

Zhang X, Kong X, 2014. Cropland sustainable use impacted by groundwater depletion in China's HHH Plains. China Land Sciences, 28(5): 90-96. (in Chinese)

Zhou D, Xu J, Lin Z, 2016. Conflict or coordination? Assessing land use multi-functionalization using production-living-ecology analysis. Science of The Total Environment, 577: 136-147.

Zhu H, 2005. Research on the coordination relationship between agricultural labor transferring and agriculture mechanization. Research of Agricultural Modernization, 26(3): 190-193. (in Chinese) 